\title{
NATURAL ISOTHIOCYANATE ANTI-MALARIA: MOLECULAR DOCKING, PHYSICOCHEMICAL, ADME, TOXICITY AND SYNTHETIC ACCESSIBILITY STUDY OF EUGENOL AND CINNAMALDEHYDE
}

\author{
LUCY ARIANIE 1 , WIDODO ${ }^{2}$, ELVINA DHIAUL IFTITAH ${ }^{3}$, WARSITO $^{3}$
}

${ }^{1}$ Chemistry Doctoral Program, Faculty of Science, Universitas Brawijaya, Malang, Indonesia, ${ }^{2}$ Biology Department, Faculty of Science, Universitas Brawijaya, Malang, Indonesia, ${ }^{3}$ Chemistry Department, Faculty of Science, Universitas Brawijaya, Malang, Indonesia

*Email: lucy.brawijaya@gmail.com

Received: 03 Jun 2021, Revised and Accepted: 25 Aug 2021

\section{ABSTRACT}

Objective: This study aims to evaluate novel compounds of isothiocyanate (ITC) based on eugenol and cinnamaldehyde derivatives as the drug candidate of Plasmodium falciparum anti-malaria using in silico method, physicochemical, pharmacokinetics, toxicity, and synthetic accessibility prediction. This present study also describes molecular docking and pharmacoinformatics of natural ITC in Moringa oleifera leaves.

Methods: A series of novel ITC compounds (3, 5, and 6) were designed and analyzed with a series of natural ITC compounds $(7,8,9,10)$ for $P$. falciparum anti-malaria. This research is descriptive qualitative and uses the reverse molecular docking method, proving the biological activity of compounds theoretically using software and database information.

Results: Molecular docking study showed that compound 6 exhibits binding affinity ( $-5.3 \mathrm{Kcal} / \mathrm{mol})$ on Van der Waals interaction with the residual active site (His159, Cys25) of cysteine protease. All designed ITC compounds are obeyed the Lipinski and Veber Rule, have a well-brain penetrant character and have a medium risk for mutagenic, tumorigenic, and reproductive prediction. They are also in the simple rate of synthetic accessibility (SA) estimation. In regards to natural ITCs, they all have better assay characteristics except the SA.

Conclusion: Molecular docking, physicochemical, pharmacokinetic, and toxicity studies show that methyl eugenol isothiocyanate and cinnamaldehyde isothiocyanate are promising anti-malaria compounds. Substituents of hydroxy, acetate and tetrahydropyran groups in the building block ring are suggested for better in silico profiles enhancement.

Keywords: Isothiocyanate, Eugenol, Cinnamaldehyde, Plasmodium falciparum, Cysteine protease

(C) 2021 The Authors. Published by Innovare Academic Sciences Pvt Ltd. This is an open access article under the CC BY license (https://creativecommons.org/licenses/by/4.0/) DOI: https://dx.doi.org/10.22159/ijap.2021v13i6.42292. Journal homepage: https://innovareacademics.in/journals/index.php/ijap

\section{INTRODUCTION}

Plasmodium falciparum malaria is a mosquito infection disease in erythrocytes that demands public attention [1-3]. Malaria long-term treatment using multidrug such as chloroquine (C) and sulfadoxinepyrimethamine causes drug resistance [4-8], increased morbidity, mortality, and health care costs [9]. The discovery of new, better bioactivity and lower toxicities drugs is focused on the abundant and renewable natural building blocks.

Active anti-malaria compound discovery has been carried out from natural sources, for instance, Eleutherine bulbosa [10] and Andrographis paniculate [11]. Eugenol and cinnamaldehyde are major components in clove essential oil (EO) and cinnamon EO. Clove (Syzygium aromaticum (L) Merr. Et Perry) and Cinnamon (Cinnamomum burmanii) plants can thrive in Indonesia and other tropical countries. The clove EO has various bioactivity potentials including antimicrobial [12-14], antifungals [15-17], anticancer [18], antiprotozoal [19], analgesic [20] and anti-inflammatory [2123]. At the same time, cinnamaldehyde derived from cinnamon EO has antiproliferative, antibacterial, and antimicrobial activity [2426]. This bioactivity predicts influenced by eugenol $\left(\mathrm{C}_{10} \mathrm{H}_{12} \mathrm{O}_{2}\right)$ and cinnamaldehyde $\left(\mathrm{C}_{9} \mathrm{H}_{8} \mathrm{O}\right)$ content as the major compound.

Molecular drug discovery is also focused on the functional group (FG) that has better bioactivity prediction. In some areas, people have used Moringa oleifera leaves for malaria treatment. It is known as a pearl of local wisdom on malaria therapy. Rhamnosyloxy benzyl isothiocyanates, the natural isothiocyanate found in $M$. oleifera leaves, are predicted responsible FG of anti-plasmodial [27]. Natural ITCs are known to have several bioactivities [28-38]. The double bond FG has partially positive and negative properties, and it is possible to carry out additional reactions into other FG. Eugenol and cinnamaldehyde have a double bond and aldehyde FG that building blocks potentially for ITC compounds. The bioactivity of eugenol-ITC and cinnamaldehyde-ITC derivatives as an anti-malaria is not known.
In the past, drug discovery was made with these categories such as time-consuming, trial and error process, high cost, and petroleumbased. Molecular docking and other bioinformatics techniques speed up the process of drug finding with better efficacy [39-41]. This recent study attempted to design ITC compounds from eugenol and cinnamaldehyde, identify its falciparum anti-malaria activities using in silico, and compare its prediction with chloroquine and natural ITC from Moringa oleifera leaves. This study will also briefly discuss the synthetic accessibility of ITC compounds.

\section{MATERIALS AND METHODS}

\section{Preparation compound and receptor}

The common structure of compounds $(1,2,4$, and $C)$ was collected in fig. 1. Novel designed-ITC $(3,5,6)$ compounds (fig. 1) and ITC derived from Moringa oleifera leaves (7, 8, 9, and 10) were constructed and converted to 3D by MarvinSketch (fig. 2). Receptor PDB ID 1YVB was obtained from the RCSB protein databank. All compounds were prepared into ligands by adding charge and hydrogen using the Chimera 1.13.1 program with the AMBERff12SB standard and Gesteiger method. The receptor was prepared and purified from water, native ligands, and its optimization was carried out by adding charge AM1-BCC and hydrogen. Molecular docking was done by PyRx and the grid dimension set as a center at $\mathrm{x}=$ 83.731069686; $y=-36.3469508554, z=-92.6668557437$ then size

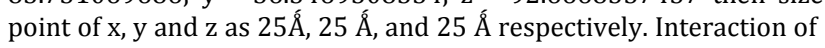
ligand with receptor was determined using affinity binding (Kcal/mol). The 3D complex structures were visualized through Discovery Studio Visualizer 2019 client.

\section{Physicochemical, pharmacokinetics, and bioactivities analysis}

Physicochemical, pharmacokinetics, and toxicities of ligands were examined respectively by Swiss ADME, Molinspiration, and Osiris. 


\section{RESULTS AND DISCUSSION}

Preparation compound and receptor for molecular docking

Docking system validation was done by redocking the native ligand of the 1YVB chain A. The precision of the docking process was determined by RMSD (Root Mean Standard Deviation) value less than 2.0. All ligands have good validation at 0.0 . The molecular docking principle is based on ligand binding interactions with active amino acids in the receptors via the presence of hydrogen bonds, Van der Waals, and electrostatic interactions. Ligand and amino acids bond distance will affect the affinity energy $(\Delta G)$ or complex stability between ligand and receptor [42]. The smaller the bond distance, the better the value of the ligand-receptor complex affinity.<smiles>C=CCc1ccc(O)c(OC)c1</smiles>

Eugenol

(1)<smiles>C=CCc1ccc(OC)c(OC)c1</smiles>

Methyl Eugenol<smiles>COc1ccc(CC(C)N=C=S)cc1OC</smiles>

4-(2-isothiocyanatopropyl)1,2-dimethoxybenzene<smiles>O=C/C=C/c1ccccc1</smiles>

Cinnamaldehyde<smiles>O=CCC(N=C=S)c1ccccc1</smiles>

3-isothiocyanato3-phenylpropanal

(5)<smiles>O=CC(Cc1ccccc1)N=C=S</smiles>

2-isothiocyanato3-phenylpropanal (6)<smiles>CCN(CC)CCCC(C)Nc1ccnc2cc(Cl)ccc12</smiles>

Chloroquine (C)

Fig. 1: Series of the building blocks $(1,2,4)$, novel ITC $(3,5,6)$, and chloroquine<smiles>[R12]OC1C(Oc2ccc(CN=C=S)cc2)OC2OC1C2O[R3]</smiles>

(7): 4-( $\alpha$-L-rhamnosyloxy)benzyl isothiocyanate $(\mathrm{R} 1, \mathrm{R} 2, \mathrm{R} 3=\mathrm{H})$

(8): 4-(2'-O-acetyl- $\alpha$-L-rhamnosyloxy)benzyl isothiocyanate (R2, R3 = H; R1 = Acetate)

(9): 4-(3'-O-acetyl-a-L-rhamnosyloxy)benzyl isothiocyanate $(\mathrm{R} 1, \mathrm{R} 3=\mathrm{H} ; \mathrm{R} 2=$ Acetate)

(10): 4-(4'-O-acetyl-a-L-rhamnosyloxy)benzyl isothiocyanate (R1, R2 = H; R3 = Acetate)

Fig. 2: Natural ITC compounds in Moringa oleifera leaves [27]

As starting material, eugenol has the same affinity with the cinnamaldehyde complex (table 1). However, OH-eugenol is predicted to inhibit the ITC group's entry, and methylation is required to form methyl eugenol (ME). It was showed that ME increased the stability complex and has a better affinity $(A G=-5.2$ $\mathrm{Kcal} / \mathrm{mol}$ ) than eugenol. Methyl eugenol isothiocyanate (ME-ITC) or 4-(2-isothiocyanatopropyl)-1,2-dimethoxybenzene has affinity -4.9 $\mathrm{Kcal} / \mathrm{mol}$. Inserting the ITC group into cinnamaldehyde resulted in 2 types of ITC prediction, namely 3-isothiocyanato-3-phenylpropanal (ligand 5) and 2-isothiocyanato-3-phenylpropanal (ligand 6). The affinity score of ligand 6 is better than its derivatives. However, both ME-ITC (ligand 3) and cinnamaldehyde-ITCs (ligand 5 and 6) could not achieve chloroquine affinity and natural ITC from Moringa oleifera leaves (ligands 7, 8. 9, and 10). In general, ligands 8 and 10 have better affinity than chloroquine. It is in accordance with the local tradition of using Moringa oleifera leaves as a traditional malaria medicine. Ligand 8 has the best energy affinity compared to chloroquine and other ligands (table 1 ).

Table 1: Binding affinities of complex 1YVB chain A with ligand

\begin{tabular}{llllll}
\hline Ligand & Affinity $\boldsymbol{\Delta G}$ (kcal/mol) & Ligand & Affinity $\boldsymbol{\Delta G}$ (kcal/mol) & Ligand & Affinity $\boldsymbol{\Delta G}$ (kcal/mol) \\
\hline 1 & -5.1 & 5 & -4.8 & -5.8 & 10 \\
2 & -5.2 & 6 & -5.3 & -6.4 \\
3 & -4.9 & 7 & -6.2 & -6 & -6.3 \\
4 & -5.1 & 8 & -6.6 & & \\
\hline
\end{tabular}




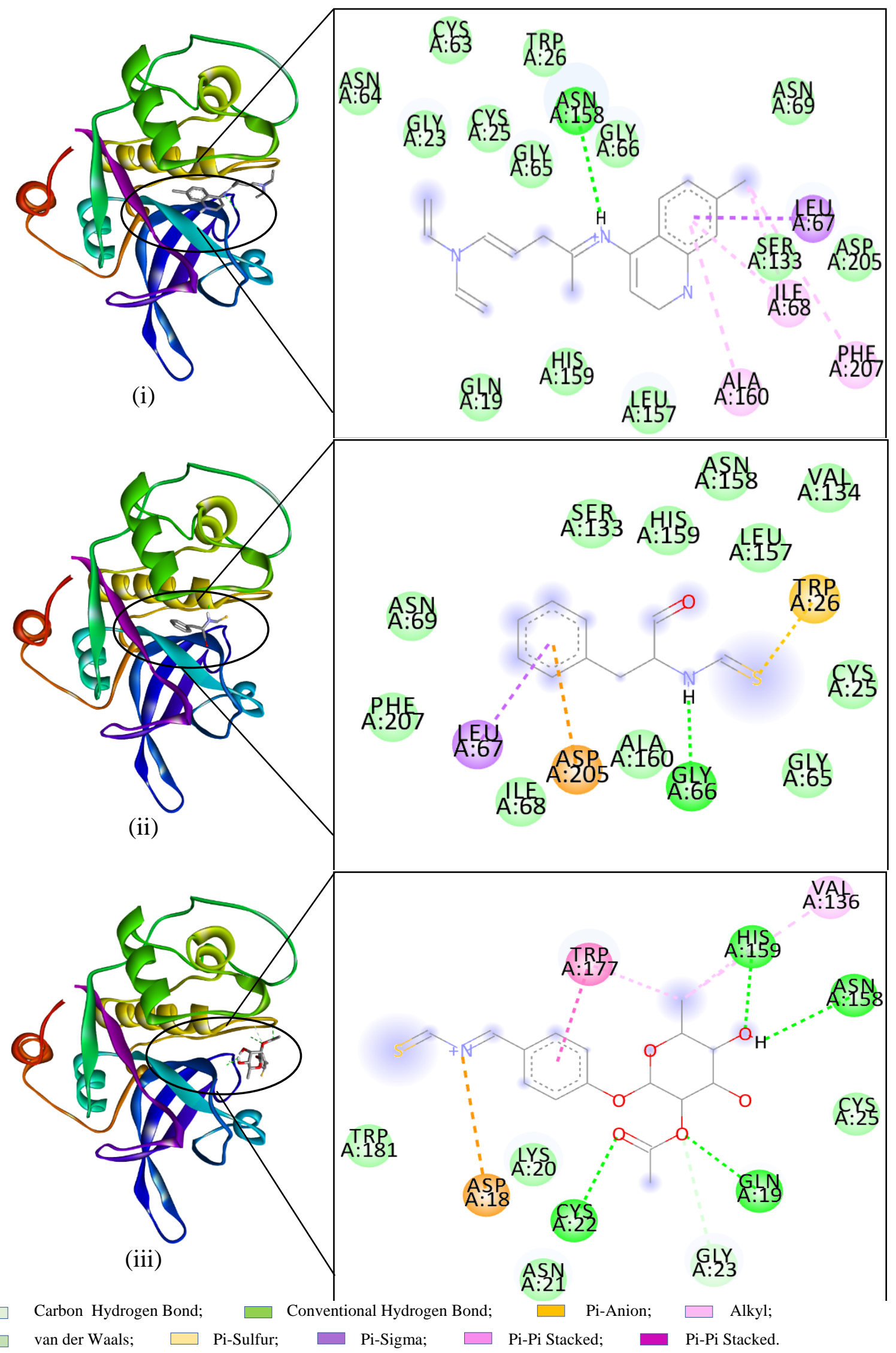

Fig. 3: The complex structure and 2D interaction of 1YVB chain A with: (i) chloroquine; (ii) ligand 6; (iii) ligand 8 
Result docking analysis is should also notice the interaction between ligand with active site residue. His159 and Cys25 residues are the active sites in the surface layer of cysteine protease responsible for the proliferation of falciparum erythrocyte [43]. Ligand 6 and C make Van der Waals link at His159 and Cys25 with its affinities $-5.3 \mathrm{Kcal} / \mathrm{mol}$ and $-6.3 \mathrm{kcal} / \mathrm{mol}$, respectively. Ligand 8 , with the lowest affinity (-6.6 $\mathrm{Kcal} / \mathrm{mol}$ ), has hydrogen bond interaction between His159 and the hydroxy group of tetrahydropyran. The Cys 25 forms. Van der Waals bonds around the sulfur double bond (fig. 3). Hydrogen bonds in the complex's residue ligand are much stronger than the Van der Waals; they stabilize the complex bonds and reduce affinity energy.

Physicochemical, pharmacokinetics, and bioactivities of compound

The physicochemical of drug candidates was measured by its properties covered by the Lipinski Rule of Five (R05) and Veber Rule [44-46]. The n-octanol/water partition coefficient (Log P) is a parameter that determines the hydrophobicity of a compound. Drug compounds' hydrophilic/lipophilic properties affect drug absorption, drug-receptor interactions, molecular metabolism, and toxicity [47]. Topological Polar Surface Area (TPSA) is a predictor of drug transport properties such as intestinal absorption and penetration of the blood-brain barrier. TPSA deals with hydrogen bonds in compounds. The number of rotatable bonds (RB) measures the flexibility of the compound related to drug absorption and bioavailability. All the ligands obeyed Lipinski and Veber Rule (table 2).

Drug candidates should have a pharmacokinetics character such as ADMET (Absorption, Distribution, Metabolism, Elimination, and Toxicological) as an integral part of screening to get the promising drug candidates [48]. ADMET is covered in drug-likeness (properties and bioactivities). The bioactivity of a drug candidate can be determined by calculating the G-Protein-Coupled Receptor (GPCR) ligand score, ion channel modulator, nuclear receptor ligand, a kinase inhibitor, protease inhibitor, enzyme inhibitor [47]. Ligands' biological activity scores of more than 0.00 are recognized as active, and less than- 0.50 are inactive [49]. The potential bioactivity of building block compounds (ligands 1,2 , and 4) and ITC designed ligands 3, 5, and 6 are moderately active. Furthermore, the native ITC in M. oleifera has a variation score around active and moderate (table 3 ).

Table 2: Physicochemical properties of ligands

\begin{tabular}{|c|c|c|c|c|c|c|}
\hline \multirow[t]{2}{*}{ Ligand } & \multicolumn{3}{|c|}{ Lipinski rule $^{*}$} & \multicolumn{3}{|c|}{ Veber rule ${ }^{* *}$} \\
\hline & MW & HBA & HBD & $\log P$ & RB & TPSA \\
\hline 1 & 164.20 & 2 & 1 & 2.37 & 3 & 29.46 \\
\hline 2 & 178.23 & 2 & 0 & 2.65 & 4 & 18.46 \\
\hline 3 & 237.32 & 3 & 0 & 2.95 & 5 & 62.91 \\
\hline 4 & 132.16 & 1 & 0 & 1.65 & 2 & 17.07 \\
\hline 5 & 191.25 & 2 & 0 & 2.14 & 4 & 61.52 \\
\hline 6 & 191.25 & 2 & 0 & 2.06 & 4 & 61.52 \\
\hline 7 & 311.36 & 6 & 3 & 2.71 & 4 & 123.60 \\
\hline 8 & 353.40 & 7 & 2 & 2.99 & 6 & 129.67 \\
\hline 9 & 353.40 & 7 & 2 & 2.50 & 6 & 129.67 \\
\hline 10 & 353.40 & 7 & 2 & 1.85 & 6 & 129.67 \\
\hline $\mathrm{C}$ & 319.88 & 2 & 1 & 3.95 & 8 & 28.16 \\
\hline *Lipinski rule: & $\begin{array}{l}\text { MW: Mo } \\
\text { HBD: hy }\end{array}$ & $\begin{array}{l}=500 \mathrm{~g} / \\
\text { nors } \leq\end{array}$ & 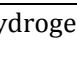 & ptors $\leq$ & & \\
\hline **Veber rule: & RB: Rot & 0 , TPS & & & & \\
\hline
\end{tabular}

All ligands are equipped with gastrointestinal absorption and brain access assays via the Brain or IntestinaL EstimateD (Boiled-Egg) permeation method for predicting lipophilicity and polarity of the drug candidate. The white egg illustrates the physicochemical space of compounds with the highest absorbed probability by the gastrointestinal tract (GI absorption), and the yellow region (yolk) is the highest permeate space to the brain (BBB permeant). Well-absorbed compound (blue point), wellbrain penetrant compound symbolized as pink point [50]. Analysis of all ligands shows that the building blocks (molecule 1,2 , and 4) have a well-brain penetrant character and are distributed in egg yolk (table 4). It also occurred to the ITCdesigned ligands and chloroquine (molecule 11). However, natural ITC (molecules 7, 8, 9, and 10) are stacked at the egg white border and assumed to be absorbed by the gastrointestinal tract (fig. 4). Ligands 1 and 2 were observed in high-risk mutagenic, tumorigenic, and irritant categories, but ligand 4 was only tumorigenic toxic. Ligands 3 and 6 dominantly have medium-risk toxicity properties, and it is a promising drug for anti-malaria. Chloroquine has a high risk of mutagenicity and irritant. Natural ITC from $M$. oleifera leaves showed mutagenic, tumorigenic, and reproductive effects at medium risk (table 5).

Table 3: Bioactivities score of ligands

\begin{tabular}{|c|c|c|c|c|c|c|}
\hline Ligand & GPCR & Ion channel modulator & Kinase inhibitor & Nuclear receptor & Protease inhibitor & Enzyme inhibitor \\
\hline 1 & -0.86 & -0.36 & -1.14 & -0.78 & -1.29 & -0.41 \\
\hline 2 & -0.81 & -0.38 & -1.06 & -0.80 & -1.14 & -0.43 \\
\hline 3 & -0.19 & -0.17 & -0.84 & -0.54 & -0.58 & 0.10 \\
\hline 4 & -1.09 & -0.39 & -1.24 & 0.96 & -0.79 & -0.46 \\
\hline 5 & -0.56 & 0.01 & -1.37 & -0.91 & -0.69 & -0.04 \\
\hline 6 & -0.37 & -0.10 & -1.18 & -0.55 & -0.17 & 0.22 \\
\hline 7 & 0.03 & 0.05 & -0.40 & -0.20 & -0.11 & 0.49 \\
\hline 8 & 0.07 & -0.03 & -0.48 & -0.12 & 0.01 & 0.46 \\
\hline 9 & 0.07 & 0.06 & -0.40 & 0.05 & 0.00 & 0.51 \\
\hline 10 & 0.07 & 0.06 & -0.40 & -0.05 & 0.00 & 0.51 \\
\hline $\mathrm{C}$ & 0.32 & 0.32 & 0.38 & -0.19 & 0.05 & 0.11 \\
\hline
\end{tabular}




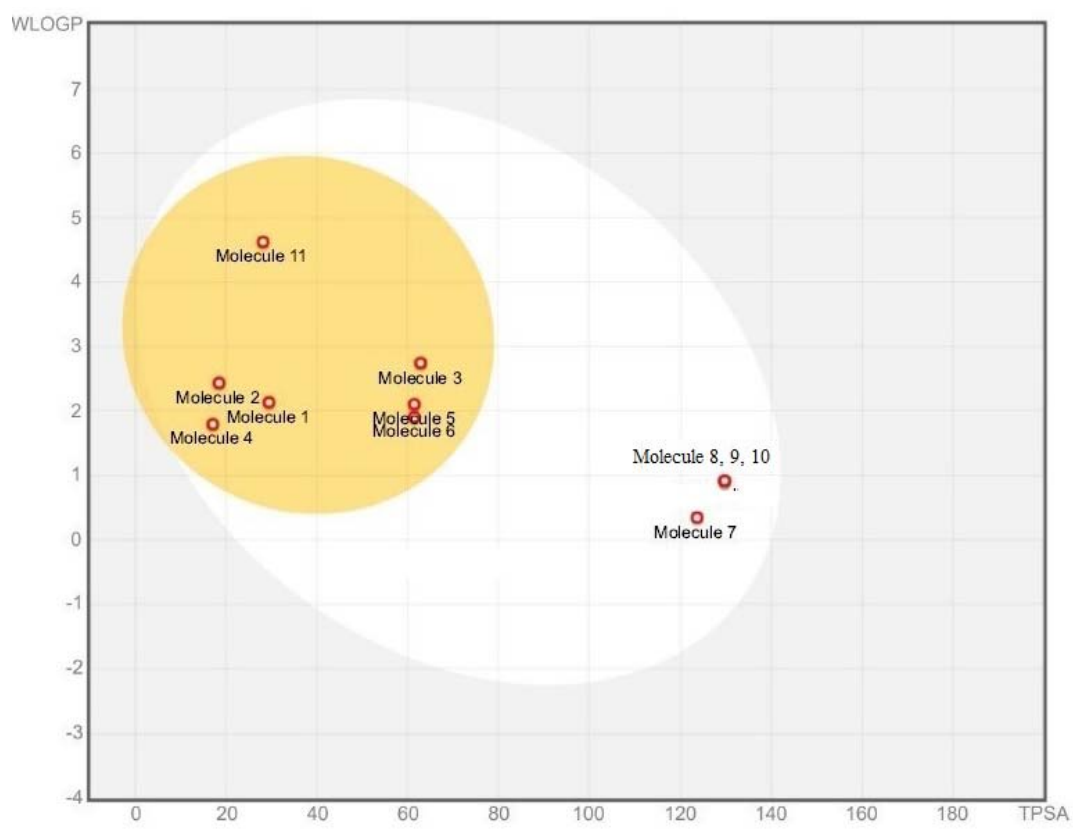

Fig. 4: Boiled-Egg model of all ligands: white area = GI absorption, yolk area = BBB

Synthetic Accessibility (SA) score is an estimation parameter of a drug designed to be synthesized on a laboratory scale. It was measured based on complexity, starting materials, or retrosynthetic-based [51]. SA score of ITC-designed ligands is between 2.14-2.51 for easily synthesized and natural-ITCs in 4.22-4.38 for moderately categories (table 4). The 8 compound has an OR group in the para position where $\mathrm{R}$ is a tetrahydropyran molecule containing an acetate group. The therapeutic activity of ITC is also influenced by aromatic and aliphatic side chains [28]. In this regard, in the design of eugenol-ITC and cinnamaldehydeITC for malaria drug purposes, the substitution of tetrahydropyran, hydroxy, or acetate groups in the building block rings should be recommended to determine better anti-malaria potential.

Table 4: Boiled-egg permeation and synthetic accessibility properties of ligands

\begin{tabular}{|c|c|c|c|c|c|c|c|c|c|}
\hline \multirow[t]{2}{*}{ Ligand } & \multicolumn{3}{|c|}{ Pharmacokinetics } & \multirow[t]{2}{*}{ SA } & \multirow[t]{2}{*}{ Ligand } & \multicolumn{3}{|c|}{ Pharmacokinetics } & \multirow[t]{2}{*}{ SA } \\
\hline & GIA & BBBp & P-gs & & & GIA & BBBp & P-gs & \\
\hline 1 & $\mathrm{H}$ & $\mathrm{Y}$ & $\mathrm{N}$ & 1.58 & 7 & $\mathrm{H}$ & $\mathrm{N}$ & $\mathrm{N}$ & 4.22 \\
\hline 2 & $\mathrm{H}$ & $\mathrm{Y}$ & $\mathrm{N}$ & 1.71 & 8 & $\mathrm{H}$ & $\mathrm{N}$ & $\mathrm{N}$ & 4.22 \\
\hline 3 & $\mathrm{H}$ & $\mathrm{Y}$ & $\mathrm{N}$ & 2.51 & 9 & $\mathrm{H}$ & $\mathrm{N}$ & $\mathrm{N}$ & 4.32 \\
\hline 4 & $\mathrm{H}$ & $\mathrm{Y}$ & $\mathrm{N}$ & 1.65 & 10 & $\mathrm{H}$ & $\mathrm{N}$ & $\mathrm{N}$ & 4.38 \\
\hline 5 & $\mathrm{H}$ & $\mathrm{Y}$ & $\mathrm{N}$ & 2.24 & $\mathrm{C}$ & $\mathrm{H}$ & $\mathrm{Y}$ & $\mathrm{N}$ & 2.76 \\
\hline 6 & $\mathrm{H}$ & $\mathrm{Y}$ & $\mathrm{N}$ & 2.14 & & & & & \\
\hline
\end{tabular}

${ }^{*}$ GIA: Gastrointestinal absorption, BBBp: Blood-brain barrier permeant, P-gs: P-glycoprotein substrate, SA: Synthetics accessibility, H: High, Y: Yes, N: No

Table 5: Toxicity prediction of ligands

\begin{tabular}{|c|c|c|c|c|c|c|c|c|c|}
\hline \multirow[t]{2}{*}{ Ligand } & \multicolumn{4}{|c|}{ OSIRIS prediction } & \multirow[t]{2}{*}{ Ligand } & \multicolumn{4}{|c|}{ OSIRIS prediction } \\
\hline & MP & TP & IP & $\mathbf{R P}$ & & MP & TP & IP & $\mathbf{R P}$ \\
\hline 1 & HR & HR & HR & $\mathrm{NI}$ & 7 & MR & MR & NI & MR \\
\hline 2 & HR & HR & HR & $\mathrm{NI}$ & $8^{* *}$ & MR & MR & $\mathrm{NI}$ & MR \\
\hline $3^{* *}$ & MR & MR & NI & MR & 9 & MR & MR & $\mathrm{NI}$ & MR \\
\hline 4 & MR & HR & MR & NI & 10 & MR & MR & NI & MR \\
\hline 5 & MR & MR & HR & MR & $\mathrm{C}$ & HR & $N I$ & HR & $N I$ \\
\hline $6^{* *}$ & MR & MR & $\mathrm{NI}$ & MR & & & & & \\
\hline
\end{tabular}

*HR: High Risk, MR: Medium Risk, NI: No Indication, MP: Mutagenic Prediction, TP: Tumorigenic Prediction, IP: Irritant Prediction, RP: Reproductive Prediction, ${ }^{* *}$ Good indication

Eugenol and cinnamaldehyde have a methylene FG, allowing addition reactions to be carried out into various other ones. The double bond addition using thiocyanic acid will produce two isothiocyanate and thiocyanate with varying yields. Isothiocyanate compounds have been synthesized from Brazilianflora limonene by transforming terminal methylene groups using potassium thiocyanate (in chloroform) for $24 \mathrm{~h}$ reaction time [52].
Synthesis of ITC in several natural compounds using amine groups has also been successfully formed with raw materials noscapine, bile acids, amino acids, and several aromatic compounds performed by transforming the-NH2 group into an ITC group [53]. The natural product that has a triple bond group, -8,15-diisocyano-11(20)-amphilectene, has been isolated from the Caribbean sponge Svenzea flava and used as a building block to form isothiocyanate derivatives [54]. Various degrees of commercial amine (primary, secondary or tertiary), cyclic, aromatic, 
and all amine positions (ortho, meta, or para) have been used to synthesize the ITC group by one-pot method and water-based at room temperature [55]. Separation and purification of ITC compounds are generally done by column chromatography or preparative Thin Layer Chromatography. Its identification is implemented mainly by Infrared, Liquid Chromatography-Mass Spectrometry (LCMS), Gas Chromatography-Mass Spectroscopy (GCMS), and High-Performance Liquid Chromatography-Mass Spectrometry [55-57] because these compounds are unstable.

\section{CONCLUSION}

Eugenol and cinnamaldehyde availability allow them to be the raw materials and building block for isothiocyanate compounds. In silico studies show that methyl eugenol isothiocyanate and cinnamaldehyde isothiocyanate are promising antimalarial compounds in terms of substituents variation such as natural isothiocyanates. This research is an invaluable essential reference for the synthesis of isothiocyanates as anti-malaria.

\section{ACKNOWLEDGEMENT}

This article is part of the doctoral thesis. Sincerely grateful to the Indonesian Ministry of Research and Technology/National Agency for Research and Innovation and the Indonesian Ministry of Education and Culture. Authors thank Universitas Brawijaya was supporting through Hibah Guru Besar 2020-2021.

\section{FUNDING}

Nil

\section{AUTHORS CONTRIBUTIONS}

All authors have contributed equally.

\section{CONFLICT OF INTERESTS}

We declare that we have no conflict of interest.

\section{REFERENCES}

1. Hasyim H, Dale P, Groneberg DA, Kuch U, Müller R. Social determinants of malaria in an endemic area of Indonesia. Malar J. 2019;18(1):134. doi: 10.1186/s12936-019-2760-8, PMID 30979370.

2. Zheng J, Pan H, Gu Y, Zuo X, Ran N, Yuan Y, Zhang C, Wang F. Prospects for malaria vaccines: pre-erythrocytic stages, blood stages, and transmission-blocking stages. BioMed Res Int. 2019;2019:9751471. doi: 10.1155/2019/9751471, PMID 31687404.

3. Barabadi H, Alizadeh Z, Rahimi MT, Barac A, Maraolo AE, Robertson LJ, Masjedi A, Shahrivar F, Ahmadpour E. Nanobiotechnology as an emerging approach to combat malaria: A systematic review. Nanomedicine. 2019;18:221-33. doi: 10.1016/j.nano.2019.02.017, PMID 30904586.

4. Bareng AP, Espino FE, Chaijaroenkul W, Na-Bangchang K. Molecular monitoring of dihydrofolate reductase (dhfr) and dihydropteroatesynthetase (dhps) associated with sulfadoxinepyrimethamine resistance in Plasmodium vivax isolates of Palawan, Philippines. Acta Trop. 2018;180:81-7. doi: 10.1016/j.actatropica.2018.01.006, PMID 29352991.

5. Kateera F, Nsobya SL, Tukwasibwe S, Hakizimana E, Mutesa L, Mens PF, Grobusch MP, van Vugt M, Kumar N. Molecular surveillance of Plasmodium falciparum drug resistance markers reveals partial recovery of chloroquine susceptibility but sustained sulfadoxine-pyrimethamine resistance at two sites of different malaria transmission intensities in Rwanda. Acta Trop. 2016;164:329-36. doi: 10.1016/j.actatropica.2016.09. 008, PMID 27647575.

6. Rogier E, Herman C, Huber CS, Hamre KES, Pierre B, Mace KE, Presume J, Mondelus G, Romilus I, Elisme T, Eisele TP, Druetz T, Existe A, Boncy J, Lemoine JF, Udhayakumar V, Chang MA. Nationwide monitoring for Plasmodium falciparum drug-resistance alleles to chloroquine, sulfadoxine, and pyrimethamine, Haiti, 2016-2017. Emerg Infect Dis. 2020;26(5):902-9. doi: 10.3201/eid2605.190556, PMID 32310062.
7. Shrivastava AK, Shrestha L, Prakash S, Mehta RK. Transgenic mosquitoes fight against malaria: a review. J Univ Coll Med Sci. 2019;7(1):59-65. doi: 10.3126/jucms.v7i1.24695.

8. Zhao L, Pi L, Qin Y, Lu Y, Zeng W, Xiang Z, Qin P, Chen X, Li C, Zhang Y, Wang S, Si Y, Yang G, Rosenthal BM, Huang Y, Yang Z. Widespread resistance mutations to sulfadoxine-pyrimethamine in malaria parasites imported to China from Central and Western Africa. Int J Parasitol Drugs Drug Resist. 2020;12:1-6. doi: 10.1016/j.ijpddr.2019.11.002, PMID 31809965.

9. Adebambo K, Gunaratnam S. Molecular docking investigation of new inhibitors of Falciparum vivax. Comput Mol Biosci. 2018;08(2):43-67. doi: 10.4236/cmb.2018.82002.

10. Ni LS, Louisa M, Astuty $\mathrm{H}$, Syafruddin D, Asih PBS. In vitro antimalarial potency of Eleutherine bulbosa and its effect on the morphology of Plasmodium falciparum. Int J Appl Pharm. 2019;11:172-6

11. Putra AMJ, Chaidir, Hanafi M, Pan Y, Yanuar A. Andrographolide and its derivative-a story of antimalarial drug design and synthesis. Int J Appl Pharm. 2017;9:1-4. doi: 10.22159/ijap.2017.v9s1.55_61.

12. Oluwasina OO, Ezenwosu IV, Ogidi CO, Oyetayo VO. Antimicrobial potential of toothpaste formulated from extracts of Syzygium aromaticum, Dennettia tripetala and Jatropha curcas latex against some oral pathogenic microorganisms. AMB Expr. 2019;9(1):20. doi: 10.1186/s13568-019-0744-2, PMID 30715633.

13. Radunz M, da Trindade MLM, Camargo TM, Radünz AL, Borges CD, Gandra EA, Helbig E. Antimicrobial and antioxidant activity of unencapsulated and encapsulated clove (Syzygium aromaticum, L.) essential oil. Food Chem. 2019;276:180-6. doi: 10.1016/j.foodchem.2018.09.173, PMID 30409582.

14. Saricaoglu FT, Turhan S. Antimicrobial activity and antioxidant capacity of thyme, rosemary and clove essential oils and their mixtures. J Inno Sci Eng. 2018;2:25-33.

15. Lima TS, França KRdS, Azevedo PTMd, Paiva YF, Silva JCS, Silva KO, Santos AB, Galdino JAAdS, Junior AFdM, Cardoso TAL. Control of some phytopathogenic fungi using clove essential oil (Syzygium aromaticum L.). JEAI:1-11. doi: 10.9734/jeai/2019/v39i330332.

16. Pilar Santamarina M, Rosello J, Gimenez S, Amparo Blazquez M. Commercial Laurus nobilis $\mathrm{L}$. and syzygium aromaticum L. Merr. \& Perry essential oils against post-harvest phytopathogenic fungi on rice. LWT- Food Sci Technol. 2016;65:325-32. doi: 10.1016/j.lwt.2015.08.040.

17. Rajkowska K, Nowicka Krawczyk P, Kunicka Styczynska A. Effect of clove and thyme essential oils on Candida biofilm formation and the oil distribution in yeast cells. Molecules. 2019;24(10):112. doi: 10.3390/molecules24101954, PMID 31117281.

18. Chua LK, Lim CL, Ling APK, Chye SM, Koh RY. Anticancer potential of Syzygium species: a review. Plant Foods Hum Nutr. 2019;74(1):18-27. doi: 10.1007/s11130-018-0704-z, PMID 30535971.

19. Batiha GE-S, Beshbishy AM, Tayebwa DS, Shaheen HM, Yokoyama N, Igarashi I. Inhibitory effects of Syzygium aromaticum and Camellia sinensis methanolic extracts on the growth of Babesia and Theileria parasites. Ticks Tick Borne Dis. 2019;10(5):949-58. doi: 10.1016/j.ttbdis.2019.04.016, PMID 31101552.

20. Kaur K, Kaushal S. Phytochemistry and pharmacological aspects of Syzygium aromaticum: a review. J Pharmacogn Phytochem. 2019;8:398-406.

21. Farris JK, Rabee AH, Naji HH, Obayes AJ, Obaid FW. Analgesic and anti-inflammatory effects of hydroalcoholic extract of (Syzygium aromaticum) in Albino mice. Kufa J Veterinary Med Sci. 2017;8:56-62.

22. Chniguir A, Pintard C, Liu D, Dang PMC, El-Benna J, Bachoual R. Eugenol prevents fMLF-induced superoxide anion production in human neutrophils by inhibiting ERK1/2 signaling pathway and p47phox phosphorylation [sci rep:18540]. Sci Rep. 2019;9(1):18540. doi: 10.1038/s41598-019-55043-8, PMID 31811262.

23. Singh V, Pahuja C, Ali M, Sultana S. Analysis and bioactivities of essential oil of the flower buds of Syzygium aromaticum (L.) Merr. et LM Perry. J Med Plants Stud. 2018;6:79-83.

24. Doyle AA, Stephens JC. A review of cinnamaldehyde and its derivatives as antibacterial agents. Fitoterapia. 2019;139:104405. doi: 10.1016/j.fitote.2019.104405, PMID 31707126. 
25. Daker M, Lin VY, Akowuah GA, Yam MF, Ahmad M. Inhibitory effects of Cinnamomum burmannii Blume stem bark extract and trans-cinnamaldehyde on nasopharyngeal carcinoma cells; synergism with cisplatin. Exp Ther Med. 2013;5(6):1701-9. doi: 10.3892/etm.2013.1041, PMID 23837058.

26. HelmyAbdou KA, Ahmed RR, Ibrahim MA, Abdel-Gawad DRI. The anti-inflammatory influence of Cinnamomum burmannii against multi-walled carbon nanotube-induced liver injury in rats. Environ Sci Pollut Res Int. 2019;26(35):36063-72. doi: 10.1007/s11356-019-06707-5, PMID 31745806.

27. Leone A, Spada A, Battezzati A, Schiraldi A, Aristil J, Bertoli S. Cultivation, genetic, ethnopharmacology, phytochemistry and pharmacology of Moringa oleifera leaves: an overview. Int J Mol Sci. 2015;16(6):12791-835. doi: 10.3390/ijms160612791, PMID 26057747.

28. Kala C, Ali SS, Ahmad N, Jamal Gilani S, Ali Khan N. Isothiocyanates: a review. Res J Pharmacogn. 2018;5:71-89.

29. Kim HY, Gornsawun G, Shin IS. Antibacterial activities of isothiocyanates (ITCs) extracted from horseradish (Armoracia rusticana) root in liquid and vapor phases against 5 dominant bacteria isolated from low-salt Jeotgal, a Korean salted and fermented seafood. Food Sci Biotechnol. 2015;24(4):1405-12. doi: 10.1007/s10068-015-0180-2.

30. Ntalli N, Caboni P. A review of isothiocyanates biofumigation activity on plant-parasitic nematodes. Phytochem Rev. 2017;16(5):827-34. doi: 10.1007/s11101-017-9491-7.

31. Arumugam A, Abdull Razis AF. Apoptosis as a mechanism of the cancer chemopreventive activity of glucosinolates: a review. Asian Pac J Cancer Prev. 2018;19(6):1439-48. doi: 10.22034/APJCP.2018.19.6.1439, PMID 29936713.

32. Tripathi K, Hussein UK, Anupalli R, Barnett R, Bachaboina L, Scalici J, Rocconi RP, Owen LB, Piazza GA, Palle K. Allyl isothiocyanate induces replication-associated DNA damage response in NSCLC cells and sensitizes to ionizing radiation Oncotarget. 2015;6(7):5237-52. doi: 10.18632/oncotarget. 3026, PMID 25742788.

33. Wu H, Feng JT, Lin KC, Zhang X. Synthesis and herbicidal activity of substituted pyrazole isothiocyanates. Molecules. 2012;17(10):12187-96. doi: 10.3390/molecules171012187, PMID 23075815.

34. Huang L, Yuan C, Wang Y. Bioactivity-guided identification of anti-adipogenic isothiocyanates in the Moringa (Moringa oleifera) seed and investigation of the structure-activity relationship. Molecules. 2020;25(11):1-9. doi: 10.3390/molecules25112504, PMID 32481514.

35. Tarozzi A, Angeloni C, Malaguti M, Morroni F, Hrelia S, Hrelia P. Sulforaphane as a potential protective phytochemical against neurodegenerative diseases. Oxid Med Cell Longev. 2013;2013:415078. doi: 10.1155/2013/415078, PMID 23983898.

36. Wilson AE, Bergaentzle M, Bindler F, Marchioni E, Lintz A, Ennahar S. In vitro efficacies of various isothiocyanates from cruciferous vegetables as antimicrobial agents against foodborne pathogens and spoilage bacteria. Food Control. 2013;30(1):318-24. doi: 10.1016/j.foodcont.2012.07.031.

37. Saladino F, Quiles JM, Luciano FB, Manes J, Fernandez-Franzon M, Meca G. Shelf life improvement of the loaf bread using allyl, phenyl and benzyl isothiocyanates against Aspergillus parasiticus. LWT. 2017;78:208-14. doi: 10.1016/ j.lwt.2016.12.049.

38. Mastuo T, Miyata Y, Yuno T, Mukae Y, Otsubo A, Mitsunari K, Ohba K, Sakai H. Molecular mechanisms of the anti-cancer effects of isothiocyanates from cruciferous vegetables in bladder cancer. Molecules. 2020;25(3):1-22. doi: 10.3390/molecules25030575, PMID 32013065.

39. Ramharack P, Soliman MES. Bioinformatics-based tools in drug discovery: the cartography from single gene to integrative biological networks. Drug Discovery Today. 2018;23(9):165865. doi: 10.1016/j.drudis.2018.05.041, PMID 29864527.

40. Ramirez D. Computational methods applied to rational drug design. Open Med Chem J. 2016;10:7-20. doi: 10.2174/1874104501610010007, PMID 27708723.

41. Zoete V, Grosdidier A, Michielin O. Docking, virtual high throughput screening and in silico fragment-based drug design.
J Cell Mol Med. 2009;13(2):238-48. doi: 10.1111/j.15824934.2008.00665.x, PMID 19183238.

42. Garcia Godoy MJ, Lopez Camacho E, Garcia Nieto J, Del Ser J, Nebro AJ, Aldana Montes JF. Bio-inspired optimization for the molecular docking problem: Sstate of the art, recent results and perspectives. Applied Soft Computing. 2019;79:30-45. doi: 10.1016/j.asoc.2019.03.044.

43. Quesne MG, Ward RA, de Visser SP. Cysteine protease inhibition by nitrile-based inhibitors: a computational study. Front Chem. 2013;1:1-10:39. doi: 10.3389/fchem.2013.00039, PMID 24790966.

44. Damiao MCFCB, Pasqualoto KFM, Polli MC, Parise Filho R. To be drug or prodrug: structure-property exploratory approach regarding oral bioavailability. J Pharm Pharm Sci. 2014;17(4):532-40. doi: 10.18433/j3bs4h, PMID 25579432.

45. Jia CY, Li JY, Hao GF, Yang GF. A drug-likeness toolbox facilitates ADMET study in drug discovery. Drug Discovery Today. 2020;25(1):248-58. doi: 10.1016/j.drudis.2019.10.014, PMID 31705979.

46. Rouane A, Tchouar N, Kerassa A, Belaidi S, Cinar M. Structurebased virtual screening and drug-like of quercetin derivatives with anti-malaria activity. Rev Theor Sci. 2017;5:1-11.

47. A CM. Determination of molecular property, bioactivity score and binding energy of the phytochemical compounds present in cassia auriculata by molinspiration and DFT method. TIJBMS 2017;2(2):8-22. doi: 10.21522/TIJBMS.2016.02.02.Art002.

48. Nastasa C, Vodnar DC, Ionuţ I, Stana A, Benedec D, Tamaian R, Oniga 0 , Tiperciuc B. Antibacterial evaluation and virtual screening of new thiazolyl-triazole sSchiff bases as potential DNA-gyrase inhibitors. Int J Mol Sci. 2018;19(1):1-18. doi: 10.3390/ijms19010222; 19010222PMID 29324679:1-18.

49. Sari DRT, Cairns JRK, Safitri A, Fatchiyah F. Virtual prediction of the delphinidin-3-O-glucoside and peonidin-3-O-glucoside as anti-inflammatory of TNF-a $\alpha$ Signaling. Acta Inform Med. 2019;27(3):152-7. doi: 10.5455/aim.2019.27.152-157, PMID 31762569.

50. Daina A, Zoete V. A boiled-egg to predict gastrointestinal absorption and brain penetration of small molecules. Chem Med Chem. 2016;11(11):1117-21. doi: 10.1002/cmdc.201600182, PMID 27218427.

51. Boda K, Seidel T, Gasteiger J. Structure and reaction based evaluation of synthetic accessibility. J Comput Aided Mol Des. 2007;21(6):311-25. doi: 10.1007/s10822-006-9099-2, PMID 17294248

52. Batista A. SAAlmeida Batista SA, Vandresen F, Falzirolli H, Britta E, de Oliveira DN, Catharino RR, Gonçalves MA, Ramalho TC, La Porta FA, Nakamura CV, da Silva CC. Synthesis and comparison of antileishmanial and cytotoxic activities of S-(--)-limonene benzaldehyde thiosemicarbazones with their R-(+)-analogues. Mol Struct. 2019;1179:252-62. doi: 10.1016/ j.molstruc.2018.11.017.

53. Babanezhad Harikandei K, Salehi P, Ebrahimi SN, Bararjanian M, Kaiser M, Al-Harrasi A. Synthesis, in vitro antiprotozoal activity and molecular docking study of isothiocyanate derivatives. Bioorg Med Chem. 2020;28(1):1-12:115185. doi: 10.1016/j.bmc.2019.115185, PMID 31784198.

54. Nieves K, Prudhomme J, Le Roch KG, Franzblau SG, Rodriguez AD. Natural product-based synthesis of novel anti-infective isothiocyanate- and isoselenocyanate-functionalized amphilectane diterpenes. Bioorg Med Chem Lett. 2016;26(3):854-7. doi: 10.1016/j.bmcl.2015.12.080, PMID 26748697.

55. Sun N, Li B, Shao J, Mo W, Hu B, Shen Z, Hu X. A general and facile one-pot process of isothiocyanates from amines under aqueous conditions. Beilstein J Org Chem. 2012;8:61-70. doi: 10.3762/bjoc.8.6, PMID 22423272.

56. Almushayti AY, Brandt K, Carroll MA, Scotter MJ. Current analytical methods for determination of glucosinolates in vegetables and human tissues. J Chromatogr A. 2021;1643:1-16462060. doi: 10.1016/j.chroma.2021.462060, PMID 33770631.

57. Kim HY, Phan-a-god S, Shin I, Phan-a-god S, Shin IS Antibacterial activities of isothiocyanates extracted from horseradish (Armoracia rusticana) root against Aantibioticresistant bacteria. Food Sci Biotechnol.. 2015;24(3):1029--34. doi: 10.1007/s10068-015-0131-y. 